\title{
An Empirical Study of the Social e-Commerce on Facebook Group Buying Services Model in Taiwan
}

\author{
Shih-Wei Hsu1 ${ }^{1}$, Chien-Chih Wang2 ${ }^{*}$, Hsin-Ling Hsieh ${ }^{2}$, Fang Qing1 \\ ${ }^{1}$ School of Information Management, Wuhan University, China. \\ 2 Industrial Engineering and Management Ming Chi University of Technology, Taiwan. \\ * Corresponding author. Tel.: +886-2-29089899; email: ieccwang@mail.mcut.edu.tw \\ Manuscript submitted October 8, 2017; accepted November 26, 2017. \\ doi: 10.17706/ijeeee.2018.8.3.130-138
}

\begin{abstract}
Most social media e-commerce platforms lack systematic logistics, financial flows, and information flows in Taiwan. This study explored the economy of closed social media fan groups, which represent a type of customer-to-customer (C2C) model. By the analysis of the current situation, we propose a three-step process that sets up the integration models for 1) the channel and stock, 2) supplier orders, and 3) consumers. The compare As-Is and To-Be logistics on the one hand and cash flows and information flows on the other, and offer corresponding plans and suggestions. The study also develops a preliminary version of the web and app for members of the community to buy the platform for testing and result validation.
\end{abstract}

Key words: Cash flow, logistics, social ecommerce, taxation, test platform.

\section{Introduction}

Online shopping is already standard behavior for many people. From personal website shopping to group shopping, they gradually transform community media into export community platforms such as Facebook and LINE. This type of shopping is called e-community business. In 2010, Mark Zuckerberg, founder of Facebook, the world's largest community website, predicted the next burst of growth in the e-commerce market to be in community business. E-commerce is more popular than ever, and people like using community sites such as Facebook, WeChat, and LINE [1], [2]. According to MIC data, 96.2\% of Taiwan's users usually use community sites, with Facebook being the most popular. Facebook users constitute $95.8 \%$ of Taiwan's population [3].

Most sellers within community media do not use a professional e-community platform, instead choosing communities such as Facebook and LINE. Therefore, the cash flow and logistics are inadequate for community platforms. If there is a system that can contain the pricing of goods, wholesalers' price, and price, among other things, the information flow between sellers and wholesalers would be clear. It would also be more convenient for the customer to make reservations. Regarding logistics, the customer chooses the delivery method, and the logistics contractor uses the system to track and confirm delivery. The reduces manual processing time and costs. "Mina Baby Mommy Buy Store" is a community on Facebook. Through understanding the origin of this community and its business model, sales practices, commodity logistics model, and the current difficulties, one could alleviate the problem and plan an e-commerce business model.

Community businesses will mature in the future [4], [5]; however, the current logistics, cash flow, 
business flow, and information flow are inadequate. Therefore, we look to Taiwanese community businesses as the focus of this problem analysis. We aim to design a system that includes an operations and logistics model that would optimize the existing and future service models. The strategy is divided into three stages, (I.) To understand the status of Taiwan's community e-commerce market. (II.) To understand the community business flow and logistics. (III.) To planning logistics with the community operators and logistics operators. The most important feature of this planning is that it provides data on logistics to the Taiwanese community, including those for establishing the operational mode for logistics circulation and the logistics service system prototype for verification.

\section{The Situation of Community e-Commerce}

A community is a group of people who share the same interests or goals and gradually understand each other and assemble as groups [6]. Such a group is critical for marketing purposes. In extant marketing research, customer cluster analysis has been a key issue for practitioners desirous of conducting accurate marketing [7]-[9]. In the case of digital customers, this is called the "online community" or the "virtual community." When community e-commerce becomes more popular., the people's use of community e-commerce platforms is becoming increasingly frequent. People customarily use community sites such as Facebook, PIXENT, Plurk, WeChat, LINE, and Weibo. Because of their high saturation levels in Taiwan according to MIC data, these community sites are used by many businesses to disseminate their product information.

Among non-self-sites, the community is at the core of the Taiwan online community; hence, consumers want to interact and do business with the communities on social media such as Facebook and LINE. There are three points of difference between traditional commerce and e-commerce:

- Third-party payment is the primary means of cash flow, and it will conform to community e-commerce as in the case of Facebook PAY.

- In logistics, community e-commerce is more stable than other forms of e-commerce because of the community. High purchase rates and human communication make the logistics more flexible.

- The main differences are preorders, shipping problems, and the mechanism of delayed shipping.

The most popular community e-commerce mode in Taiwan is through Facebook, divided between fan clubs and groups. Fan clubs are more successful with community e-commerce because they operate as open shops and have multiple systems, such as marketing data analysis and customer management [10]. Through this feature, the seller understands the store better. However, Facebook groups are more closed to membership than are fan clubs and are divided into three different types: public, private, and secret groups. Most sellers choose their model by whether the group is open or not. Each group has a leader who runs the team. This is a standard marketing technique.

Community businesses provide many business opportunities but can cause particular problems as well. In marketing, Facebook can be used to disseminate many messages simultaneously. However, if untargeted, this strategy could cause fray people's tempers. Facebook is complicated to customize to an exclusive look at the sizes, colors, and font types are limited. The means that catching the attention of viewers becomes more difficult when compared with traditional layouts. When it comes to managing transactions in groups, members can just contact the concerned parties on Facebook, and it is not easy to attract new members because the group is closed. Groups are different from fan clubs in that they do not generate data for analysis and users need to scan the data by themselves. The posts are affected by consumers' preferences and time efficiently. Also, groups have operational problems such as order processing and customer service questions, among other things. The As-Is model of Facebook's group shipping is shown in Fig. 1. 


\section{Case Study}

Wish Grass Co., Ltd., is our research object. The company's suppliers have jewelry factories and plastic injection facilities, among other things. Their primary trading platforms are their blog, Yahoo, PChome, and Momo. The supply chain of the company has global businesses, small businesses, and factories. Their part in the relationship is limited to disseminating information on goods, providing order information, and conducting consignment delivery. Through a self-marketing platform, Wish Grass sells products to the sellers through e-commerce and conducts group shipping through Facebook; those sellers are called "Group-Moms." The Group-Mom usually posts information on goods on the Facebook group page. Customers order products by leaving a message. Customers have two settlement options: transfer or cash payment. When the Group-Mom receives payments for goods, they transfer the money to Wish Grass, which in turn sends the products to the Group-Mom's home. If these items are large, then Wish Grass send the products to the consumer's address. Other products allow customers to choose the delivery method; for example, customer pick-up, through a convenience store, or by home delivery as shown in Fig. 2.

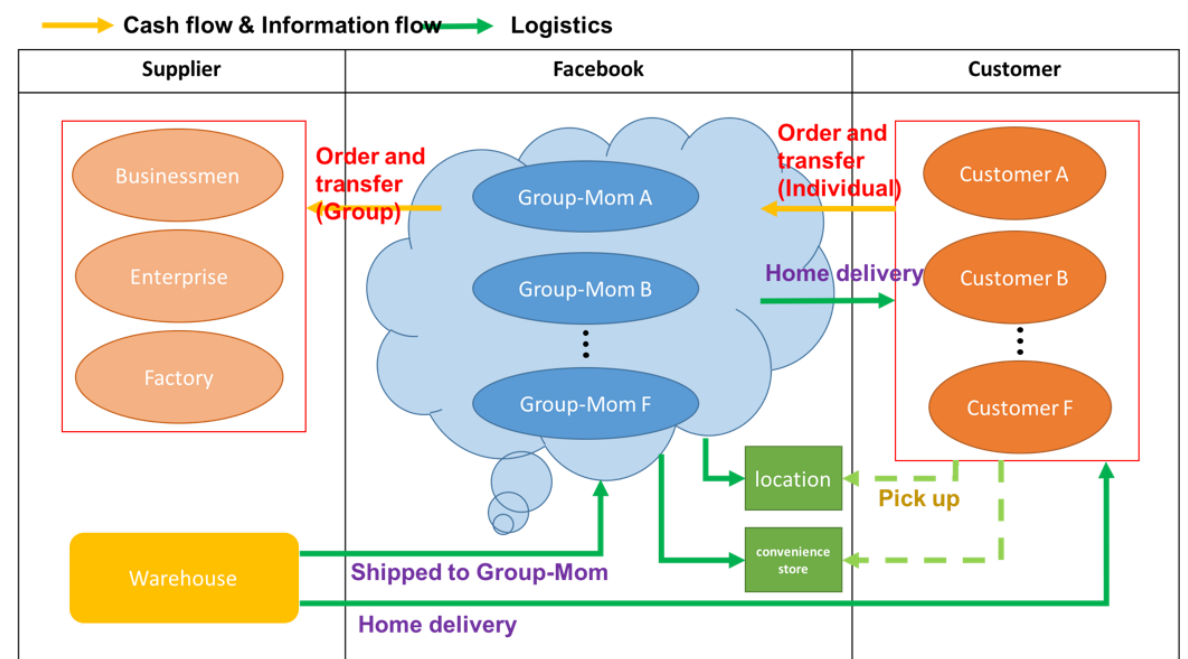

Fig. 1. As-Is model ofFacebook' s group shipping.

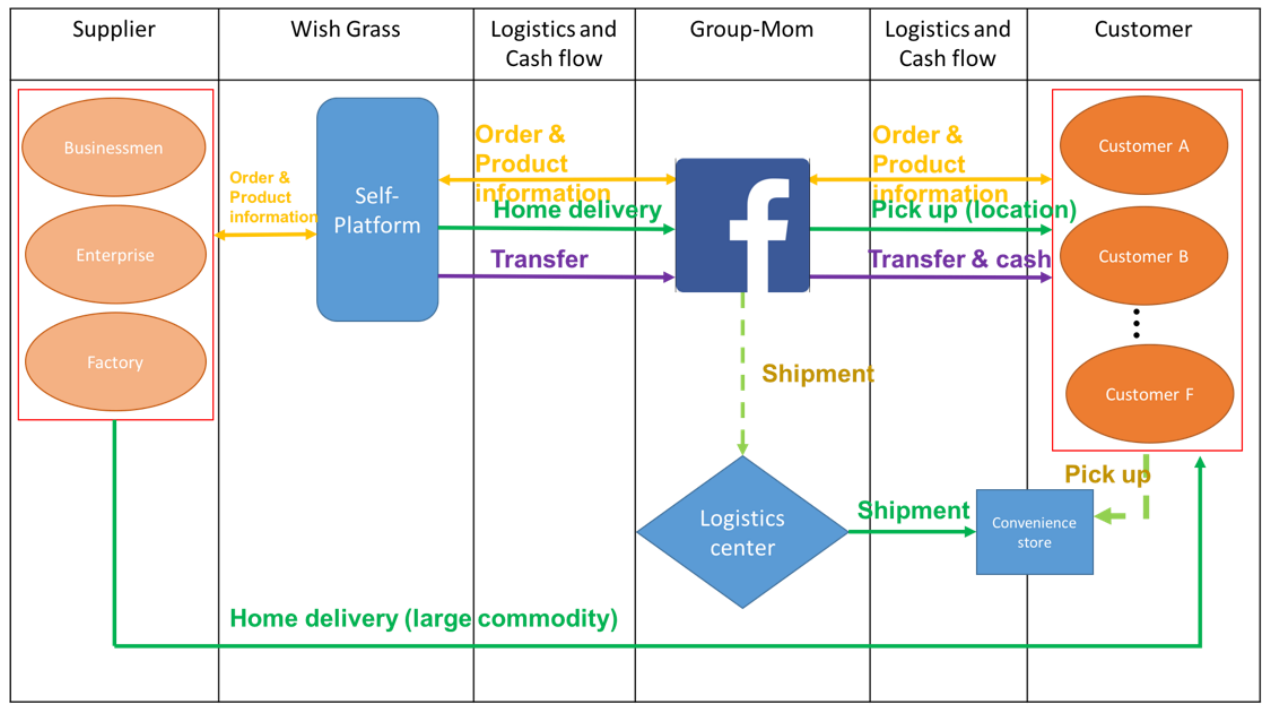

Fig. 2. Wish grass's supply chain analysis.

After discussing this issue with manufacturers, this research found that the logistics, cash flow, business 
flow, and information flow of Taiwan's e-commerce community are not perfect, particularly when dealing with orders and logistics using mostly manual processes. If the company can develop a system on Facebook that can attract Group-Moms by enabling them to use the system for selling wares, it would augur well for all parties.

In a development that can let one another's information be made public, this study has developed a system including pricing, wholesale price, price, and other information, thus proposing more convenient order consolidation for the Group-Mom. About logistics, saving freight and optimizing speed are the most significant concerns for industry; hence, convenience stores are necessary for allowing consumers to pick up their goods. However, the industry will need to spend human resources, money, and time to deal with products.

From the preceding discussion, this research summarizes the issues concerning community e-commerce as follows:

- Lack of systematic information systems:

Facebook is a community website that does not provide services such as logistics and those required to facilitate and monitor cash flow. The risk involved in this platform is relatively high because its function within the community is not ideal for dealing with orders made by human beings.

- Lack of efficient logistics systems:

Most Group-Moms process shipments by themselves and determine the cost of logistics according to delivery requirements. In simple terms, improving logistics efficiency is not the primary service; however, as the number of orders increases, Group-Moms are required to increase the number of workers to process the requests as delays may cause customers to complain.

\section{Model Analysis and Planning}

The flow of the community e-commerce business model is from the supplier to the Group-Mom and then from the Group-Mom to the customers. We aim to save transfer time and provide quick delivery to customers. After our discussion with the manufacturer, we concluded that the Group-Mom stage is skipped and that goods be transferred directly to the customers by an intermediary as shown in Fig. 3. The not only improves the smoothness of the transaction but also reduces the time required for processing orders.

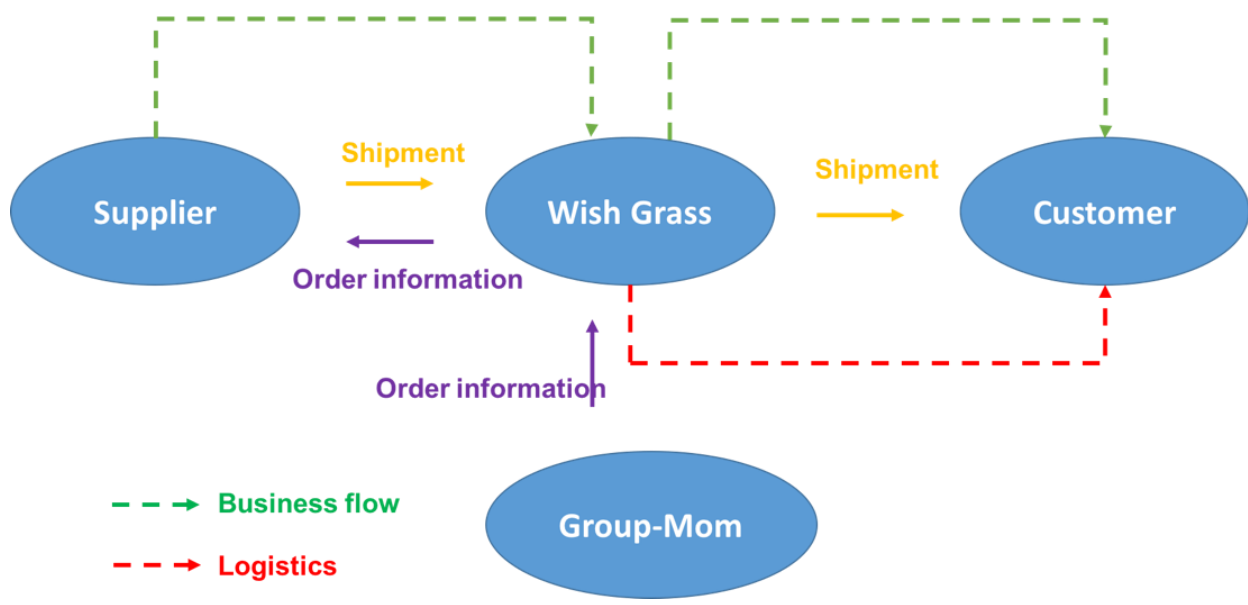

Fig. 3. Improved model of business flow and logistics.

The logistics model is divided into three types: delivery service, convenience store delivery service, and pick-up by the customer. Most customers like to pick up items themselves; however, from the manufacturer's perspective, direct delivery is preferable regarding cost. This way, the problem of keeping 
the goods in Group-Moms' homes is obviated and the delivery (logistics) time is decreased.

Up until now, Group-Moms transmitted information on the number of goods to the manufacturers, who then aggregated the information for the shipping supplier. To eliminate the need to aggregate data in the Group-Mom step, we should ask the Group-Mom for data regarding the order and apprise the manufacturers of the order information simultaneously, thereby reducing the logistics cost involved in achieving our goal.

The research for the current situation analysis results proposes the model shown in Fig. 4. The main model consists of three parts. The integrated model of the channel and the inventory, that of the supplier's order, and that of the customer's order. In the integrated model of the channel and the inventory, we propose using the system to incorporate the goods into the stock, having the supplier update the information on the network, and then determining the logistics plan and distributing the goods on the basis of the order. In the integrated model of the supplier's order, we propose providing the order format to the Group-Mom, which can be more convenient when the supplier gathers statistical information regarding the goods. Through this system, the Group-Mom can check the order status (cash flow and logistics). The integrated model of the customer's order can provide an order format to the client. This way, the Group-Mom's statistics can speed up the order by the transferance of the order directly to the supplier. The Group-Mom can check the status of the order (logistics and cash flow) using the order query function.

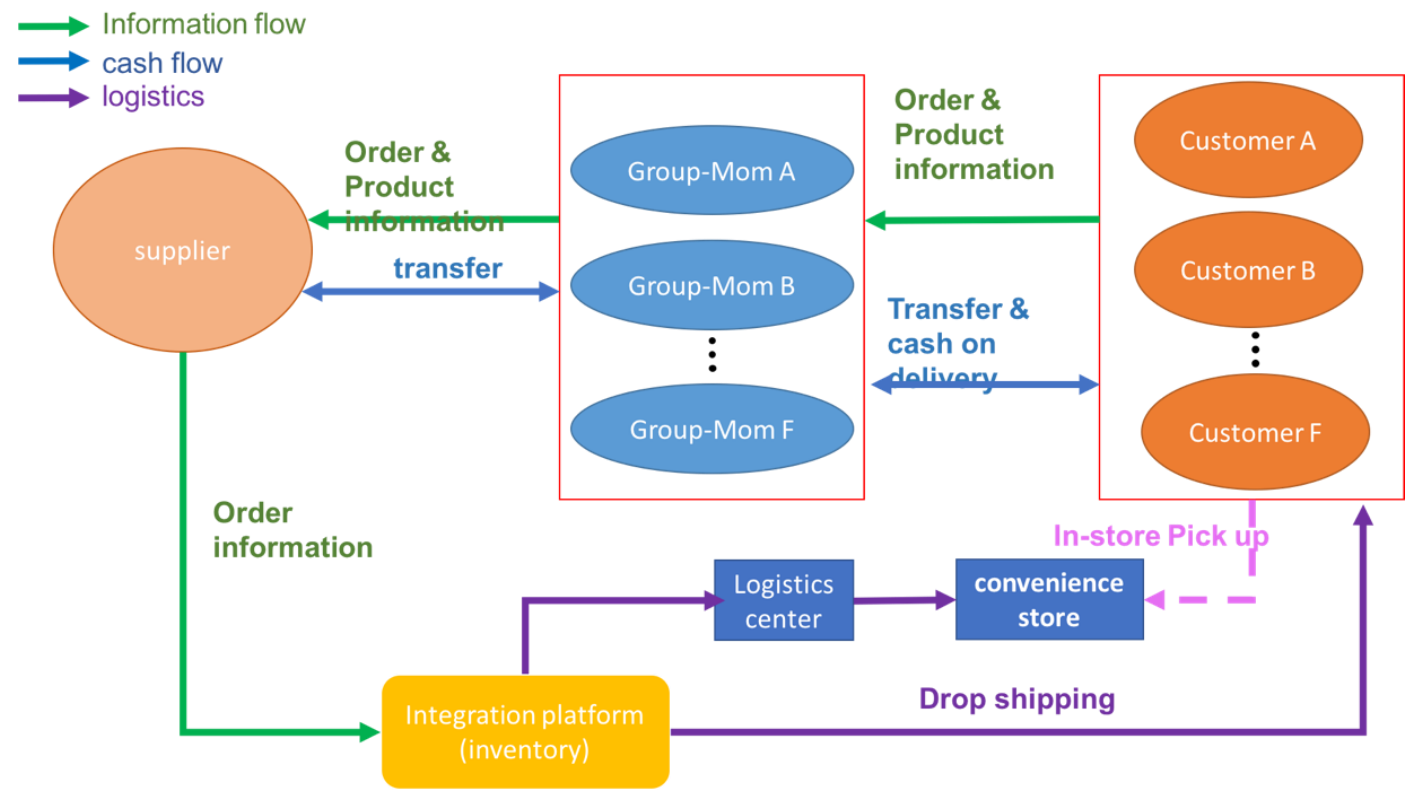

Fig. 4. Logistics and cash flow models in this research.

In 2016, David Marcus, Vice President of Facebook's Messaging Products, announced that users could pay using Messenger robots without connecting to other, external sites. Users who store credit card-related information on Facebook or Messenger can shop by using the Messenger robots. It was slated to collaborate with Stripe, PayPal, Braintree, Visa, MasterCard, and American Express. The cash flow of Taiwanese community e-commerce promises to introduce third-party payments in the future. In Table 1, when community e-commerce presents third-party payments, the former becomes a complete cash flow cycle as in the case of other e-commerce platforms.

The third-party payment platform is a neutral third-party payment organization with an individual asset and reputation and provides the cash flow service. This organization is not restricted to the business model (whether financial or non-financial). It involves the use of the organization's information technology that 
includes connecting to user accounts, providing payment information, taking custody of the payment, and transferring the payment. Fast and secure payment methods have become the primary payment modes for customers. Today, the model of cash flow is more convenient when the third-party payment organization is well known and provides the convenience of use. The third-party payment organization is a fair third-party that protects the rights of customers and creates a real trading environment for sellers.

Table 1. Comparison Cash Flows of e-Commerce, Facebook (As-Is), and Facebook (To-Be)

\begin{tabular}{|c|c|c|c|}
\hline Cash Flow & E-commerce & $\begin{array}{c}\text { Group-shipping on Facebook } \\
\text { (As-Is) }\end{array}$ & $\begin{array}{c}\text { Group-shipping on Facebook } \\
\text { (To-Be) }\end{array}$ \\
\hline Transfer & $\mathrm{V}$ & $\mathrm{V}$ & $\mathrm{V}$ \\
\hline Internet transfer & $\mathrm{V}$ & $\mathrm{V}$ & $\mathrm{V}$ \\
\hline Credit card & $\mathrm{V}$ & & $\mathrm{V}$ \\
\hline Stored account & $\mathrm{V}$ & $\mathrm{V}$ & $\mathrm{V}$ \\
\hline $\begin{array}{c}\text { Billing to mobile phone and } \\
\text { landlines }\end{array}$ & $\mathrm{V}$ & $\mathrm{V}$ & $\mathrm{V}$ \\
\hline Cash on delivery & $\mathrm{V}$ & $\mathrm{V}$ & $\mathrm{V}$ \\
\hline Physical path & $\mathrm{V}$ & & \\
\hline
\end{tabular}

\section{Application System Analysis and Planning}

After discussions with Wish Grass, this research hopes to design a system that includes product pricing, wholesale price, price, and other information and provides a clear flow of information between the wholesalers and the Group-Mom. Therefore, it will be more convenient when the Group-Mom's statistical information is known. Fig. 1 and Fig. 5, respectively, show the Facebook community e-commerce relationships: As-Is and To-Be. In the To-Be model, the main idea is to help suppliers in sending orders to the logistics center by using the information system and logistics providers. Table 2 describes the differences between the Group-Mom use of the development platform and Facebook community platforms. Group-Moms subsequently package and ship the goods to the customer as required.

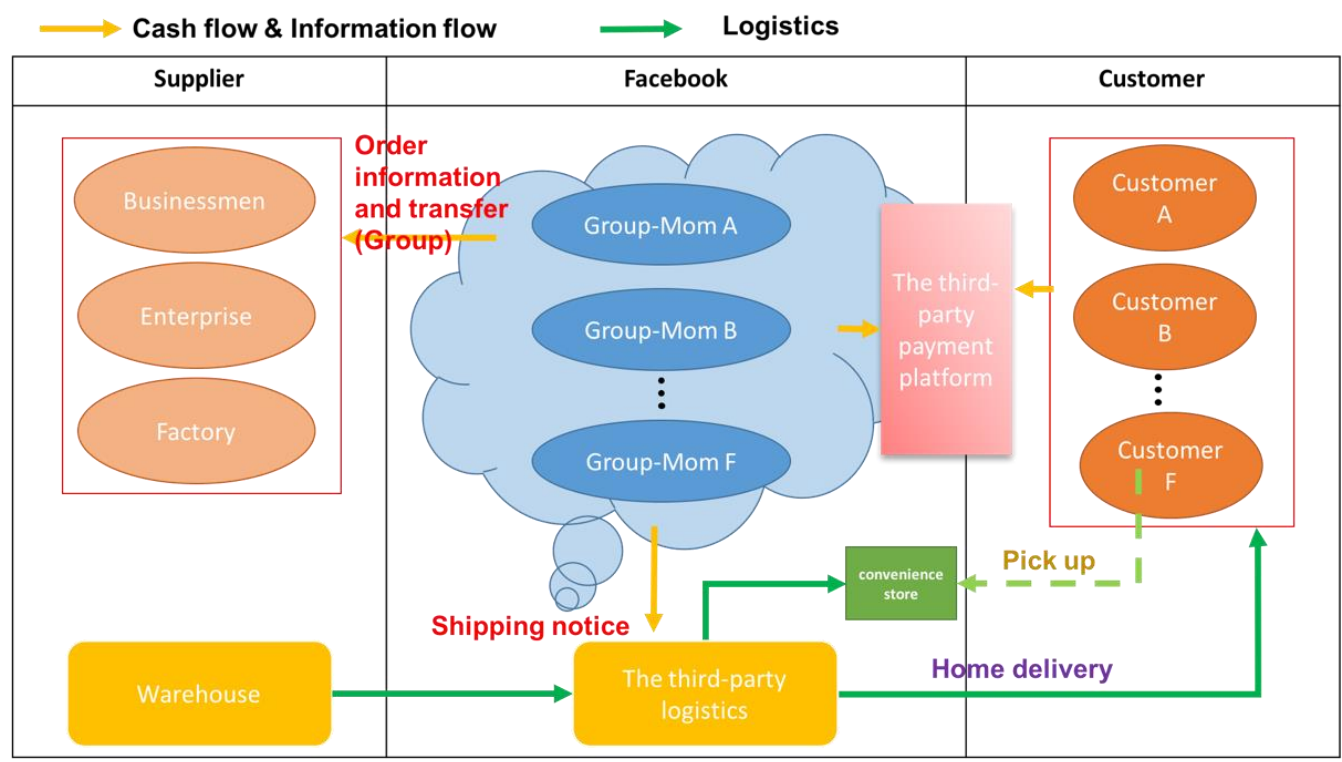

Fig. 5. Community e-commerce on Facebook (to-be model).

In the design of the circulation and logistics service system, this research develops an app and web system as shown in Fig. 6. 
Table 2. Differences between the Group-Mom and Community Platforms

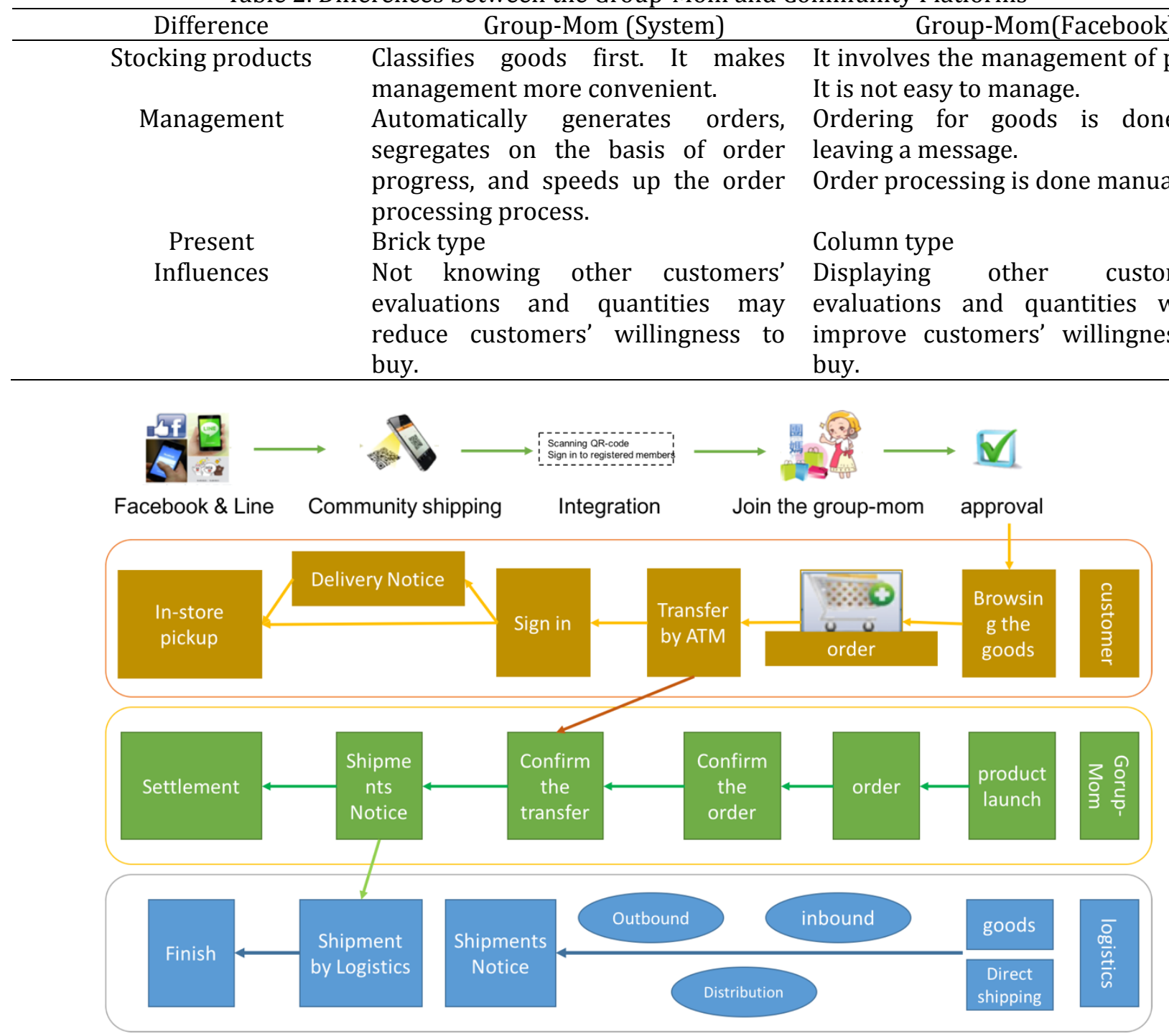

Fig. 6. Flow frame of the proposed system.

\section{Conclusion}

In this study, we provide some information regarding the integration of the manufacturing to order system and the logistics operators into the system and the provision of an available model of information flow and business flow to the Group-Mom. (1.) Use robots to stock products, and use the integrated system for statistical data. Automatically generate orders by leaving a message on Facebook. (2.) Use the information platform to collect statistics, and provide a checking platform. (3.) Provide information regarding the state of the goods to the customer. This service includes the state of logistics, orders, and cash flows. (4.) Collaborate with a third-party financial organization that provides payment services such as credit cards, ATM, and those at convenience stores. (5.) Work with a third-party financial group to establish electronic invoicing.

To logistics suppliers, logistics means providing balanced logistics services to the Group-Mom. It divides the cost into the freight and processing fees. In community e-commerce, logistics is king as it can process stock, develop new products, and recommend goods. In the operational performance forecast, community e-commerce is at the core of operations. Savings in the cost of information and logistics (third-party) are the first profit result. 


\section{References}

[1] Katawetawaraks, C., \& Wang, C. L. (2011). Online shopper behavior: Influences of online shopping decision. Asian Journal of Business Research, 1(2), 66-74.

[2] Ho, H. Y., \& Pan, H. Y. (2010, August). Use behaviors and website experiences of Facebook community. Proceedings of 2010 International Conference on Electronics and Information Engineering (ICEIE) (Vol. 1, pp. V1-379). IEEE.

[3] Chen, Y. C. (2014). The Current Situation and Application of Brand Development. Market Intelligence and Consulting Institute, Taiwan.

[4] Becker-Olsen, K., \& Guzmán, F. (2017). Corporate Social Responsibility Communication in North America: The Past, Present and Future. In Handbook of Integrated CSR Communication (pp. 293-315). Springer International Publishing.

[5] Campbell, J. M., \& Park, J. (2017). Extending the resource-based view: Effects of strategic orientation toward community on small business performance. Journal of Retailing and Consumer Services, 34, 302-308.

[6] Lu, Y., Zhao, L., \& Wang, B. (2010). From virtual community members to C2C e-commerce buyers: Trust in virtual communities and its effect on consumers' purchase intention. Electronic Commerce Research and Applications, 9(4), 346-360.

[7] Punj, G., \& Stewart, D. W. (1983). Cluster analysis in marketing research: Review and suggestions for application. Journal of Marketing Research, 134-148.

[8] Brusco, M. J., Singh, R., Cradit, J. D., \& Steinley, D. (2017). Cluster analysis in empirical OM research: Survey and recommendations. International Journal of Operations \& Production Management, 37(3), 300-320.

[9] Ryu, K., \& Lee, J. S. (2017). Examination of restaurant quality, relationship benefits, and customer reciprocity from the perspective of relationship marketing investments. Journal of Hospitality \& Tourism Research, 41(1), 66-92.

[10] Koh, J., \& Kim, Y. G. (2004). Knowledge sharing in virtual communities: an e-business perspective. Expert systems with applications, 26(2), 155-166.

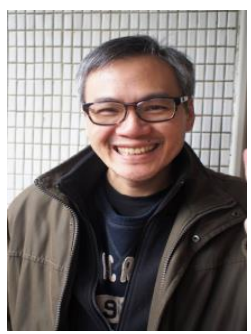

Shih-Wei Hsu is currently studying a Ph.D at the School of Information Management, Wuhan University, Wuhan, China. His research focuses on the topic of online-to-offline (020) commerce, including those in both traditional and digital publishers. small and medium-sized (and micro) enterprises. He held an important post in a top-3 EC company in Taiwan, and participated in enterprise transformation of several companies.

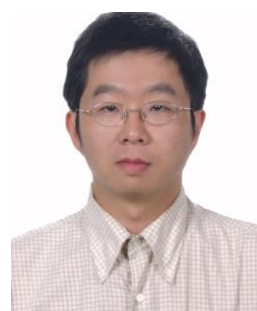

Chien-Chih Wang is a professor in the industrial engineering and management at Ming Chi University of Technology in Taiwan. He received the B.S. degree in applied mathematic from National Chung Hsing University in 1992, and the M.S. degree in statistics from the University of National Cheng Kung University in 1994, and the Ph.D. degree in industrial engineering and management from Yuan Ze University in 2001. His current research activities include service quality, quality engineering, data mining and six sigma methodology and applications. 
Hsin-Ling Hsieh received the M.S degree in the industrial engineering and management at Ming Chi University of Technology, Taiwan, in 2017. Her research focuses on the topic of quality of service quality, e-commerce and especially in social e-commerce.

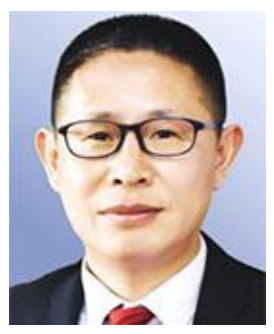

Fang Qing is a professor and dean in the School of Information Management at Wuhan University. His research interests include marketing in publishing industry, marketing in cultural industry, management of digital publishing industry and scientific communication. 